Phase-1) links placed on partner websites only; Phase-2) active promotion by partners and earned media added; Phase-3) paid media added. Results/Outcome Each phase increased Website visits (2044; 3921; 9313), including a $137.5 \%$ increase due to paid media in Phase- 3 (\$10 000 Facebook, plus \$20 000 various websites). Facebook was the leading source of Phase-3 traffic (2515 visits), but yielded average visits of only $15 \mathrm{~s}$ and $89.5 \%$ of visitors bounced (exited homepage without viewing other pages). In comparison, website visits increased $149.4 \%$ during a 2 -week period in Phase-2 following a press release (379 visits), with average visits of $1: 49 \mathrm{~min}$ and a bounce rate of $44.8 \%$.

Significance/Contribution to the Field Results demonstrated the potential of and revealed trade-offs inherent to paid and earned media for promoting a web-based injury prevention programme. Paid media had high costs and brought high traffic volume, but website use by visitors was limited. Earned media was free, increased website traffic less than paid media, but visitors used the website more. The success of earned media is encouraging for programmes that have limited financial resources.

\section{COMPARING PAID VERSUS EARNED MEDIA PROMOTIONAL STRATEGIES TO BROADLY DISSEMINATE AN EFFECTIVE TEEN DRIVING INTERVENTION TO MICHIGAN PARENTS VIA THE WEB}

doi:10.1136/injuryprev-2012-040590t.15

${ }^{1} \mathrm{CR}$ Bingham, ${ }^{1} \mathrm{JT}$ Shope, ${ }^{1} \mathrm{~J}$ Zakrajsek, ${ }^{2} \mathrm{~A}$ Esdale, ${ }^{2} \mathrm{~L}$ Scarpetta. ${ }^{1}$ University of Michigan Transportation Research Institute, USA; ${ }^{2}$ Michigan Department of Community Health, USA

Background Effective injury prevention programmes for teen drivers that can be broadly disseminated are needed. In this study, a university and a state department of community health partnered to translate an evidence-based, parent-oriented teen driving intervention to a website for state-wide dissemination.

Aims/Objectives/Purpose Compare the effectiveness of website promotion efforts via paid or earned media.

Methods Three, 4-month sequential phases of an incremental promotional strategy were evaluated using data from Google Analytics: 